\title{
A real-world experience: Really?
}

\author{
R. Scott Mitchell, MD
}

From the Department of Cardiovascular Surgery, Stanford University, Stanford, Calif; and the VA Palo Alto Health Care System, Palo Alto, Calif.

Disclosures: Author has nothing to disclose with regard to commercial support.

Received for publication May 18, 2018; revisions received May 18, 2018; accepted for publication May 21, 2018; available ahead of print July 3, 2018.

Address for reprints: R. Scott Mitchell, MD, 300 Pasteur Dr, Falk CV Research Center, Stanford, CA 94305 (E-mail: rsmitch@stanford.edu).

J Thorac Cardiovasc Surg 2018;156:2074-5

0022-5223/\$0.00

Published by Elsevier Inc. on behalf of The American Association for Thoracic Surgery https://doi.org/10.1016/j.jtcvs.2018.05.082

The report by Mkalaluh and colleagues ${ }^{1}$ in this issue of the Journal presents data on thoracoabdominal aortic aneurysm repair as a "contemporary collective" of patients undergoing open surgical repair in a non-high volume center, with mortality and morbidity "comparable to high-volume centers." As a believer in the volumeoutcome relationship, I found this surprising, especially for such a complex procedure with such high associated morbidity. Surgical outcomes for 38 patients during a 10-year interval were reported. By comparison, Coselli and coworkers $^{2}$ in Texas presented a study cohort of 3346 patients who underwent open TAAA repair during a 29-year period. Admittedly, Coselli and coworkers ${ }^{2}$ set a high bar, but there are multiple centers with annual volumes larger than 15 to 20 patients.

In their article, Mkalaluh and colleagues ${ }^{1}$ report an overall surgical mortality of $10.5 \%$ for the entire cohort. That cohort included, however, 18 patients with connective tissue disorders and 20 without such disorders. For purposes of comparison, let us assume that patients with connective tissue disorders were younger than 50 years. Their mortality was $0 \%$. These are not atypical results, because these patients are younger, with far fewer comorbidities. For patients who did not have connective tissue disorders, and were likely older than 50 years, mortality was $20 \%$ (4/20). For the Texas patients, ${ }^{2}$ mortality for patients younger than 50 years was $3.25 \%$, versus $8.2 \%$ for those older than 50 years. Although the Heidelberg data ${ }^{1}$ are certainly confounded by small numbers (the Achilles' heel of statistical comparisons), I suspect that this represents a real difference. Similarly, length of hospital stay differed greatly, at 21.5 days (16-35 days) in the study of Mkalaluh and colleagues ${ }^{1}$ versus 12 days (9-17 days) in the study of Coselli and coworkers, ${ }^{2}$ although intensive care unit stays did not, at 3.5 days (2.3-21.5 days) versus 4 days (3-7 days), respectively.

Perhaps more importantly, does this in fact represent a real-world experience? In a recent article $^{3}$ describing TAAA repairs in the state of California performed between 1995 and 2010, 122 hospitals performed only

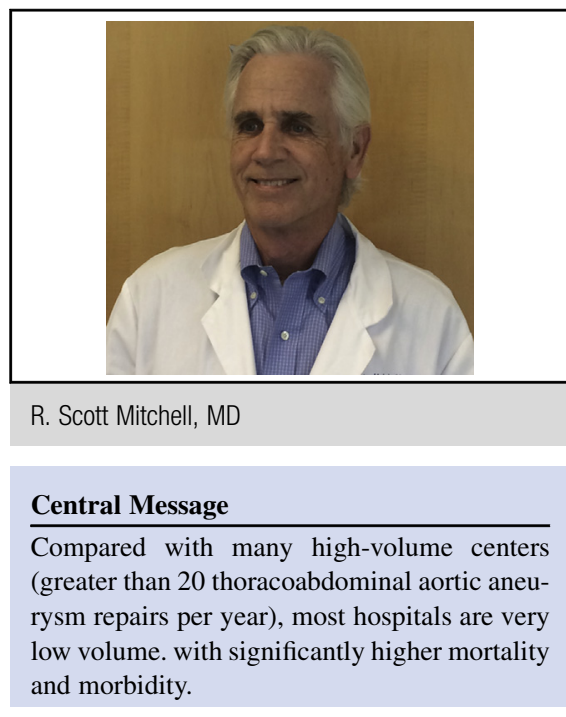

See Article page 2067.

1188 such procedures, or about 10 procedures per hospital during the 15 -year period. Only 5 hospitals received a classification of high volume, defined as having performed 9 or more TAAA repairs in any single year. Overall mortality was $23.9 \%$, which I think does, in fact, represent a real-world experience, with too many small hospitals performing large, complex operations for which they are ill-equipped. Compare a mortality of $8.2 \%$ for Cambria and associates ${ }^{4}$ in 445 TAAA repairs during a 19-year span and Coselli and colleagues' report ${ }^{5}$ with a mortality of $4.8 \%$ in 1220 TAAA repairs during 12 years versus a nationwide average of $20.3 \% .^{6}$ These results seem to support the volume-outcome relationship. This is even more concerning considering new 4 branch endografts are soon to hit the market, which will surely reduce further the volume of open surgical repairs. Would we not be better served by creating regional centers with dedicated hospital resources, processes, and perioperative support for these infrequent and highly complex procedures?

\section{References}

1. Mkalaluh S, Szczechowicz M, Dib B, Weymann A, Szabo G, Karck M. Open surgical thoracoabdominal aortic aneurysm repair: the Heidelberg experience. J Thorac Cardiovasc Surg. 2018;156:2067-73.

2. Coselli JS, Amarasekara HS, Green SY, Price MD, Preventza O, de la Cruz KI, et al. Open repair of thoracoabdominal aortic aneurysm in patients 50 years old and younger. Ann Thorac Surg. 2017;103:1849-57. 
3. Weiss A, Anderson JA, Green A, Chang DC, Kansal N. Hospital volume of thoracoabdominal aneurysm repair does not affect mortality in California. Vasc Endovascular Surg. 2014;48:378-82.

4. Conrad MF, Crawford RS, Davison JK, Cambria RP. Thoracoabdominal aneurysm repair: a 20-year perspective. Ann Thorac Surg. 2007;83: S856-61.
5. Coselli JS, Conklin LD, LeMaire SA. Thoracoabdominal aortic aneurysm repair: Review and update of current strategies. Ann Thorac Surg. 2002;74:S1881-4; discussion S1892-8.

6. Derrow AE, Seeger JM, Dame DA, Carter RL, Ozaki CK, Flynn TC, et al. The outcome in the United States after thoracoabdominal aortic aneurysm repair, renal artery bypass, and mesenteric revascularization. J Vasc Surg. 2001;34:54-61. 